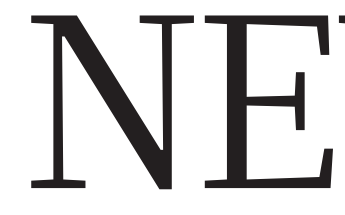

SPENDING US ocean sciences panel calls for infrastructure cuts $\mathbf{p . 5 3 8}$
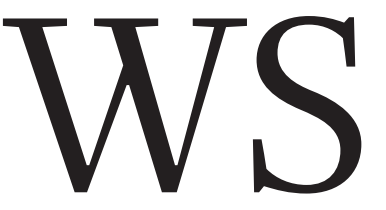
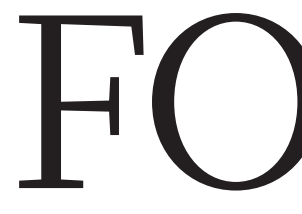
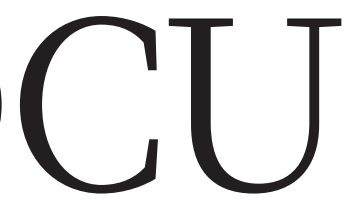

S

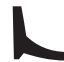

\begin{tabular}{|c|c|c|}
\hline cuts p.538 & dilemma p.536 & the-scenes staff $\mathbf{p . 5 4 2}$ \\
\hline
\end{tabular}

SPACE Lost comet lander poses science-mission dilemma p.536
HEALTH Obama floats precision-medicine programme $\mathbf{p . 5 4 0}$
UnSUNG heroes The snake milker and other behindthe-scenes staff $\mathbf{p . 5 4 2}$

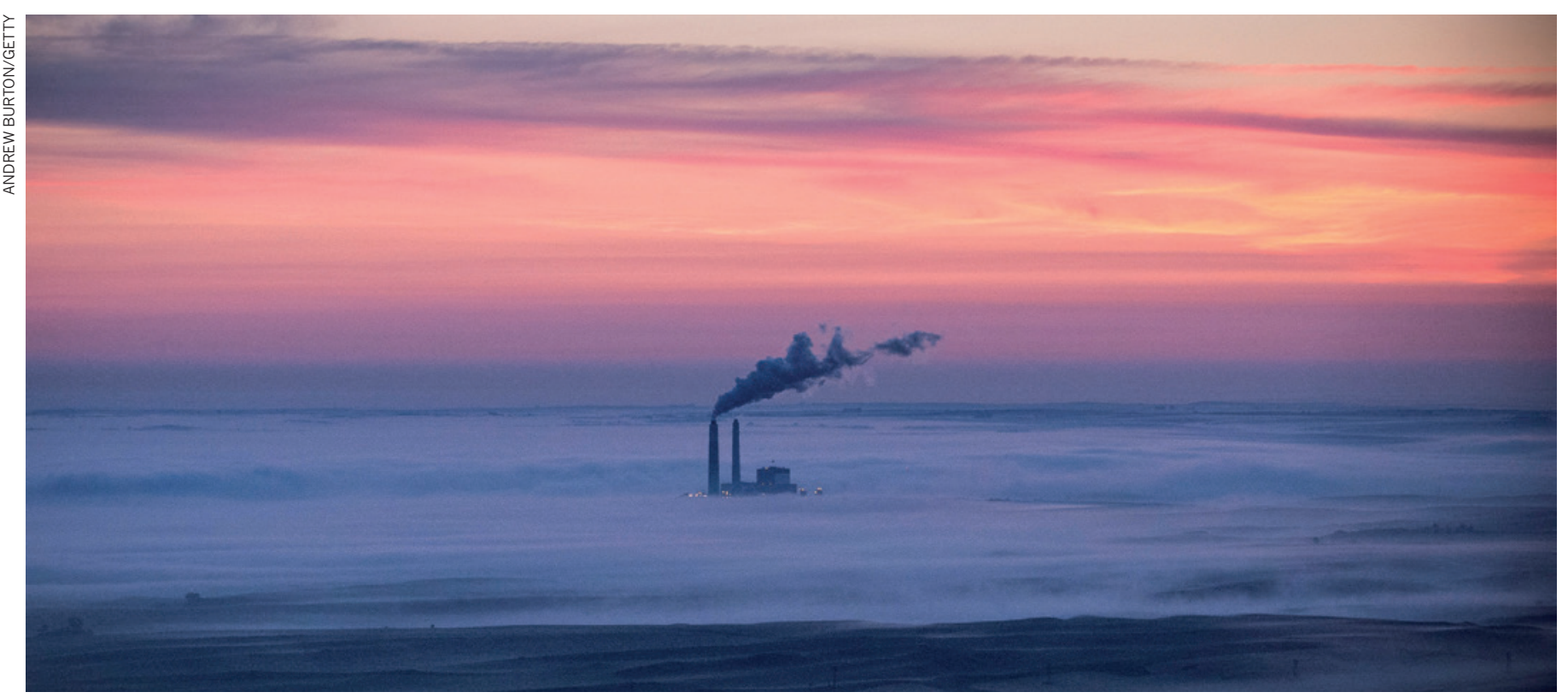

Regulations affecting coal-burning power plants are key to US President Barack Obama's effort to reduce greenhouse-gas emissions.

\title{
Obama acts alone on climate
}

\section{With little hope of support from Congress, US president unilaterally pushes regulations and international agreements in pursuit of an environmental legacy.}

\section{BY JEFF TOLLEFSON}

$\mathrm{T}$ The collapse of legislation to reduce US greenhouse-gas emissions was one of the most significant failures of President Barack Obama's first term in office. Halfway through his second, in the face of an entrenched Republican majority on Capitol Hill, Obama is now trying to build an environmental legacy through actions that he can take without congressional approval.

"Over the past six years, we've done more than ever to combat climate change, from the way we produce energy to the way we use it," the president said in his annual State of the Union address to Congress on 20 January. "I will not let this Congress endanger the health of our children by turning back the clock on our efforts."

Although environmentalists had hoped for more progress when Obama came into office, most give him credit for having done what he has in the face of Republican opposition. "Obama has done an amazing amount on climate in his six years, and it certainly looks like he is trying to make this a legacy issue," says Kevin Kennedy, director of the US Climate Initiative at the World Resources Institute, a non-governmental environmental-research organization in Washington DC.

The administration is currently pushing regulations to reduce carbon dioxide emissions from existing US power plants, and methane from oil and gas production. On the international front, Obama secured a deal in November with Chinese President Xi Jinping that commits both countries to reducing greenhouse-gas emissions over the next 10-15 years (see Nature 515, 473-474;2014). The United States is also pushing domestic and international measures that would reduce emissions of hydrofluorocarbons, powerful greenhouse gases that are often used as refrigerants. The president has the authority to make international agreements and issue regulations independent of Congress, both houses of which came under Republican control with November's elections.

The long-term success of these efforts will depend on court rulings and the actions of future administrations. The power-plant regulations in particular will be essential if the United States is to meet its commitment under the US-China agreement to reduce emissions by at least $26 \%$ below 2005 levels in the next decade. Due to be finalized in mid-2015, the standards as proposed would reduce emissions from the electricity sector by $30 \%$ and build on emissions reductions that have been achieved over several years through a shift away from using coal. That shift was spurred by falling natural-gas prices, tightening of air-pollution 
- regulations and the growth of renewable energy sources, especially wind power.

But first, the regulations must withstand inevitable industry lawsuits intended to weaken or overturn them. "The power-plant rule is really pivotal to Obama's legacy, and it is going to face tough legal scrutiny," says David Victor, director of the Laboratory on International Law and Regulation at the University of California, San Diego. If it succeeds, he adds, "it could reverse the position of the United States internationally".

Although Obama was unable to secure climate legislation during his first term, his administration did achieve gains in the wake of the recession. It secured billions of dollars in stimulus funding for clean energy, efficiency measures and green infrastructure, as well as establishing significant new standards for vehicle emissions and fuel economy. That, combined with the economic slowdown and the shift away from coal in the electricity sector, means that US greenhouse-gas emissions have already decreased by around $10 \%$ since 2005 .

In theory, the administration still has both the time and the means to reduce emissions

enough for the United States to meet its international commitments, says Kennedy. "They will have to take very serious action, but the tools that they have available to them should allow them to do it."

Republicans have vowed to challenge Obama at every turn. They started the current session with a debate on legislation to approve the con-

\section{"The power-}

plant rule is

really pivotal to

Obama's legacy, and it is going to face tough legal scrutiny." troversial Keystone XL pipeline, which would carry crude oil from the tar sands of Alberta, Canada, to refineries on the US Gulf Coast. The House of Representatives quickly passed a bill to approve the pipeline, but partisan disagreements have delayed a Senate vote. Obama has promised to veto the legislation.

Although the pipeline would have a small effect on global greenhouse-gas emissions, it has become a symbolic issue for both sides of the climate debate. On 21 January, Senate Democrats used the Keystone fight to confront Republicans on their views about climate by putting to a vote declarations about human involvement in global warming (see Nature http://doi.org/zpx; 2015). Fifteen Republicans supported an amendment to the Keystone bill stating that climate change is affected by human activity, and five voted for an amendment stating that climate change is "significantly" affected by humans.

Although neither amendment passed, those votes are a sign that Republicans are feeling pressure and may warm to certain climate solutions in future, says Bob Inglis, a Republican former member of the House who heads the Energy and Enterprise Initiative, a think tank that advocates for conservative environmental solutions at George Mason University in Fairfax, Virginia. Although Inglis understands why Obama has chosen to sidestep Congress and address climate change with regulations, he says that the president still has a potential opportunity to secure his environmental legacy by striking a grand legislative bargain with his Republican opposition.

"Obama is in a box," says Inglis, "but he could get out of that box if he were a little bit bolder." - SEE EDITORIALP. 527

\section{Philae hunt hangs in the balance}

\section{Rosetta mission would have to sacrifice other science to search for comet lander.}

\section{BY ELIZABETH GIBNEY}

$\mathrm{T}$ The lost space probe Philae, which made history after it landed on a comet last November, is posing a dilemma for scientists at the European Space Agency (ESA). They have what is probably their last chance to change the path of Philae's parent craft, Rosetta, to hunt for the lander, which went missing shortly after it touched down on comet 67P/Churyumov-Gerasimenko. But the shift would also mean sacrificing some of Rosetta's long-planned science observations.

The agonizing choice comes as the mission team published its first batch of papers from observations made after Rosetta entered into orbit around 67P last August - reporting a varied landscape and hinting at the comet's origins.

Philae has been silent since its batteries ran out just days after its bumpy landing on 12 November. On the basis of images of its initial bounces and data from radio instruments, Philae's position has been narrowed down to a 20 -metre by 200 -metre strip. But efforts to find the 1-metre-wide lander in highresolution pictures taken by Rosetta from a distance of about 20 kilometres have so far failed.

\section{NEARLY WEIGHTLESS}

The resulting effect of gravitational potential and centrifugal forces, mapped on coment $67 \mathrm{P} /$ Churyumov-Gerasimenko, is revealed to be greatest on the lobes and weaker in the neck region.

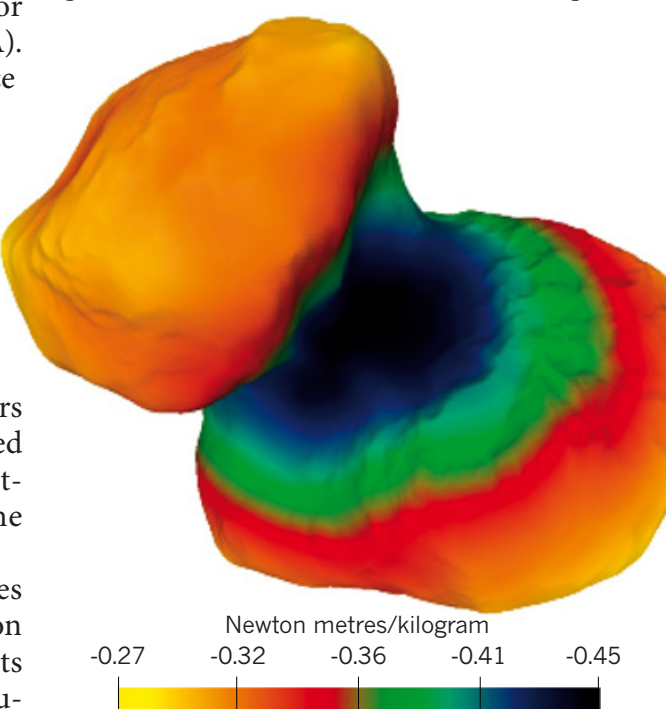

Project scientists are debating whether to send Rosetta, which is still orbiting the comet, down to an altitude of 6 kilometres, over the patch where Philae is thought to be. It would be the closest that the craft has ever been to 67P. But Rosetta has limited fuel. Any attempt to look for Philae would mean scrapping a different flyby, which would offer the chance to image the comet in a shadow-free shot that should reveal fine details about the surface structure and composition.

As the comet approaches the Sun, growing cometary surface activity in the form of jets of gas and dust also makes it increasingly risky for Rosetta to approach. If Rosetta is to stick to the original flyby plan, scheduled for 14 February, the craft will not come as close to 67P until 2016, says the mission's flight director Andrea Accomazzo, after the comet has swung around the Sun and headed back out to space.

\section{SURFACE SEARCH}

There are scientific benefits to pinpointing Philae's location, says Wlodek Kofman, principal investigator on Rosetta's CONSERT (Comet Nucleus Sounding Experiment by Radiowave Transmission) experiment, which is designed to send radio waves between the

\section{ONATURE.COM}

For the best images from Rosetta's data haul, see:

go.nature.com/rrihsj 